\title{
THE SOUTH-EAST LONDON GENERAL PRACTITIONER CENTRE
}

\author{
Brigadier H. L. Glyn Hughes, C.B.E., D.S.O., M.C., M.R.C.S., L.R.C.P. \\ The South-East London General Practitioner Centre, St. Mary's Road, London, S.E. 5
}

THE background of this project dates back to 1955 when discussions first took place between representatives of the London County Council, the South-East Metropolitan Regional Hospital Board, the College of General Practitioners and the London Local Medical Committee to explore the possibility of establishing a centre where diagnostic and treatment facilities would be available to local general practitioners, and it might also be possible to. undertake the undergraduate teaching of general practice.

The London County Council had for a long time wished to use such a centre to establish medico-social research facilities, and the college to undertake general practitioner research.

Meetings took place in 1956 at which considerable interest was shown by the local doctors and it could be assessed that there would be adequate support for the scheme to go ahead. In 1957 the London County Council reached agreement with the Ministry of Health and the London Executive Council and gave authority for the formation of a committee to explore all the possibilities and to enter into discussions with those bodies who would be concerned. Final approval was given by the Ministry of Health in November $195^{8}$.

A small and enthusiastic band of local family doctors had never wavered in their allegiance to the concept of this Centre and, throughout the years from 1956 onwards, worked energetically on the various detailed problems concerned with the ultimate form and administration of the unit. The Director was appointed in $195^{8}$ to enable him to take a full part in the detailed planning of the Centre and to assist in co-ordinating the wishes of the local doctors who were the inspiration behind the scheme.

The Centre was ceremonially opened on February 16, 1961, by the Lord Cohen of Birkenhead and ready to receive patients on March I, which is its official birthday.

This is, in fact, a pioneer project and the only one of its exact kind in the United Kingdom. It is for this reason that the words 'health centre' do not appear in the title of the unit. The two other centres, which can be labelled as diagnostic centres, at Corby and Edinburgh, resemble it to some extent but each have their differences.

\section{The Centre, its Objects and the Facilities Available}

The basic object of the Centre is to provide diagnostic facilities for the family doctors in the neighbourhood, to enable them to investigate fully those of their own patients who do not necessarily need a specialist opinion, and to complete their clinical examinations. Consultant advice is, however, available to them, should they so wish it, from a general physician, a pathologist, and a radiologist who attend to supervise the reporting of the investigations that have been carried out in their respective departments.

Parallel to these are the facilities available to them for minor operative procedures and the treatment of their patients, and the use of the consulting rooms, nursing staff and specialist equipment for more intensive examinations. These amenities have proved to be helpful in timesaving in that the doctors can be assured of an appointment system for these purposes and that nursing staff and sterilized equipment, etc., will be ready for them when they arrive. It does enable them to put into practice the skills for which they have been trained.

A health visitor has an office in the Centre and is available to deal with social problems.

The advance of medicine, with new drugs, new techniques, and the help available from social workers does now enable the general practitioner to treat many more of his patients without sending them to hospital. The availability of the resources of the Centre has acted as a stimulant; the feeling of increased responsibility has acted as an incentive to better general practice and without doubt helps to increase the stature of the general practitioner and to raise his status in the eyes of his patienis. At the same time, it provides a service which is appreciated by the patient in that his own family doctor can complete the clinical investigation, and he will not be compelled to attend a hospital 
outpatient department with its fresh contacts and the possibility of delay.

At the outset there was some scepticism as to the need for this Centre and its success, particularly as it is situated in an area where there has been 'open access' in the neighbouring general hospitals from the inception of the National Health Service, and there are normally not long delays in the provision of outpatient appointments. However, this fear has not materialized; the success of the experiment probably stems from the wish of the good family doctors to do better medicine, but possibly, without their realizing it, from the fact that they have come to look on it as something of their own, and for this reason utilize it whenever they can. For cases which may require frequent progress reports it is invaluable as the doctors might be diffident in worrying hospital departments too often for this purpose. For this reason it has become a very live local medical centre. The quick service has been very much appreciated by the patients, who, even with hospital appointments, may be subjected to quite long delays.

To a reasonable extent patients can choose the timing of their appointments and, if these are made before the mid-afternoon, for all ordinary investigations the general practitioner will get the report next day. The atmosphere is not that of a hospital and one feature which has impressed itself on the nurses and technicians is that the investigation and treatment of young children is carried out with much less fuss and distress than is the case in the austerity of a hospital department.

To summarize the facilities that are available at the Centre. They are:

I. An X-ray Department-up to the present time no barium investigations have been undertaken, and, even with the more powerful apparatus which is to be installed there is no intention of including these for the time being.

2. A Pathological Department-here are carried out the normal requirements of a general practitioner in hæmatology, in bacteriology and to a much lesser extent in bio-chemistry.

3. Electrocardiography - this is a facility which is very much appreciated and is becoming an increasing requirement.

4. An Allergy Service-with skin sensitization tests.

5. The services of a Health Visitor-to deal with social problems.

6. Trained Nursing Staff-available to assist in treatment, minor operative procedures and investigations.

7. The attendance of Consultant Staff-to supervise their departments and who are available should general practitioners wish tôे discuss with them any special problems.

8. The gradual building up of a Library and aro Information Service on all matters which could be of use to family doctors.

The large common room is perhaps the moss important room of all. Something of this kind is really essential in any unit which it is proposed to establish as a focal centre where doctors can meet $\frac{\bar{s}}{\bar{D}}$ where conferences and case discussions can tak place and where social engagements can be arranged. It is invaluable for postgraduate meet $=$ ings and education. As evidence of this, regula? buffet luncheons are arranged and, at these, tap $\vec{\xi}$ recordings of value to general practitioners are played over; at the end a consultant in the specialt involved is available to answer any questions; the whole proceeding is carried through in the space्s. of one hour and a quarter and enables doctors tos meet each other on common ground much moret frequently than they otherwise would do. The्్ lunches are always very well attended. Various medical organizations have used the common room for their evening meetings throughout the past year.

When the idea of the Centre was first conceived various suggestions were made for its use, aparto from the diagnostic and treatment facilities to 8 provided. These included the instruction undergraduates in general practice, the conducto medico-sociological research, general practitione research, the possibility of organizing a sterile syringe service and a cutting and photo-copyingo service in conjunction with the facilities afforded by the College of General Practitioners.

\section{Work Done in the First Year}

It was decided to wait until it was seen whether the Centre was a success before embarking on anything very ambitious, and it is only now, after: a full year's working, that it is possible to form. conclusions as to the way in which some of these projects might be carried out. Already, however믐 a start has been made with some research which is only possible at the general practitioner level, and experiments are in progress to discover the values of expendable syringes and other materials when. compared with the provision of a sterile syringer service and sterile packs.

Before proceeding to discuss the future and the relation of this Centre to the original concept of health centres and a comparison with those that are in being, figures showing the work carried out during the past year should be of value. (Sees? Table r.)

From these figures it can be seen that the useof the Centre has grown steadily and that it must. have filled a gap in the life of the general prac $\frac{\stackrel{\mathbb{D}}{0}}{2}$ 
TABLE I.

\begin{tabular}{|c|c|c|c|c|c|c|c|c|c|c|}
\hline Time & & & Patients & X-Ray & Path. & E.C.G. & Allergy & Nursing & Ops. & Total \\
\hline $\begin{array}{l}\text { March to August .. } \\
\text { September to February }\end{array}$ & $\begin{array}{l}\cdots \\
\cdots\end{array}$ & 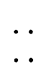 & $\begin{array}{l}2,236 \\
2,694\end{array}$ & $\begin{array}{r}905 \\
1,117\end{array}$ & $\begin{array}{l}1,005 \\
1,261\end{array}$ & $\begin{array}{l}159 \\
163\end{array}$ & $\begin{array}{l}68 \\
61\end{array}$ & $\begin{array}{l}493 \\
715\end{array}$ & $\begin{array}{l}69 \\
64\end{array}$ & $\begin{array}{l}2,699 \\
3,381\end{array}$ \\
\hline Year $1961-62$ & .. & . & 4,930 & 2,022 & 2,266 & 322 & $129 *$ & 1,208 & 133 & 6,080 \\
\hline
\end{tabular}

*This represents 10 months only.

The number of doctors using the Centre in the first year was 106.

titioners of the neighbourhood, and enabled them to practise better medicine. Careful statistics have been kept from the commencement and a morbidity survey carried out by classification of every patient passing through the Centre, under a 'disease' heading. From this it should be possible to evaluate the pattern of work and morbidity in general practice in the area and the ordinary requirements of a family doctor. It may prove of interest that there is a large coloured population in the area which may provide a factor in some conditions.

It has not yet been possible to investigate whether the advent of the Centre has in any way altered outpatient attendances at the neighbouring general hospitals; the first impression is that it has not overall, but it will be worth a study of figures in relation to special departments.

\section{Finance}

It has not yet been possible to estimate either the capital or the maintenance cost of the Centre, but this is being carried out and should form a valuable comparison with health and diagnostic centres established in recent years. It should enable an assessment to be made of the intrinsic worth of this unit and its ability to take a place in the National Health Service pattern, possibly more economically than the provision of health centres as originally conceived and which have not, in all cases, been a success.

The original capital cost of this Centre was borne by the London County Council, the Nuffield Foundation, the Sir Halley Stewart Trust and the South-East Metropolitan Regional Hospital Board.

No charge has been made to the general practitioner towards the maintenance costs.

It is of interest that the Centre was established in part of the building which previously housed what was known as the Peckham Experiment. This could perhaps be described as the pioneer of health centres but was, strictly speaking, a 'Family Club' which provided a health service with periodic medical examinations and various ancillary services for infants, children and parents.
The building at the time of its erection in 1935, and designed by Sir E. Owen Williams, was a new concept in architecture and, it is understood, was the first of its kind in the country.

\section{The Future}

It is very much hoped that in the foreseeable future it will be possible to implement those original suggestions which have not yet been commenced, in particular medico-sociological research and undergraduate teaching of general practice. If more space becomes available it may also be of advantage to bring into the Centre certain of the services provided by local health authorities, to organize in those that are suitable the participation of general practitioners, and thereby secure the closer integration between the three sections of the National Health Service which is so desirable.

\section{Undergraduate Education}

There is an increasing trend in the teaching hospital and an increasing and expressed wish on the part of students themselves for undergraduate education to include much more of the medical and social problems met with in general practice, and for actual contact with general practice as carried out by family doctors 'on the ground'. Many teaching hospitals have attachment schemes by which students spend a specified time with a general practitioner. These vary considerably, and there are many ways in which a student could be taught the rudiments of general practice; lectures are of little use by themselves except to sow the seed.

It is hoped that it may be possible to organize a constructive use of the Centre for this purpose and to co-ordinate attachment schemes with doctors who use the Centre and the closer study of general practice, by seminars, case conferences and case work by students with individual families.

\section{Postgraduate Education}

There is scope at the Centre for all forms of postgraduate education. Many meetings of academic bodies have already taken place; these have 
included both film presentation and tape recordings, and it should be possible to arrange clinical evenings. There is also unlimited opportunity to organize general practitioner research and the morbidity survey which has been carried out should provide a good basis for further investigations.

Consideration of the future must include thought concerning the value of establishing other units such as this within the structure and pattern of the National Health Service. This cannot be done without comparing it with the original concept of health centres which local authorities were empowered to provide under Section $2 \mathrm{I}$ of the National Health Service Act (1946) and with those that have actually been started since the Act came into being in 1948. The facilities that could be provided under Section $2 \mathrm{I}$ of the Act were very comprehensive and very much wider than anything envisaged for diagnostic centres such as Edinburgh or South-East London. The basic difference is that, in the original conception and in many centres that have been started, family doctors actually carry on their practice in them, either wholly or in part. It is this reason that may explain to some extent their non-success and the difficulty in organizing sufficient health centres to include more than a very small number of general practitioners in any area. The idea of 'group practice' is growing throughout the country; in it, two or more doctors practise from a central surgery and, depending on the numbers, it is possible to provide the extra amenities and ancillary help which can lead to a better service for the patient and a more easily organized life for the busy practitioner.

The conditions under which family doctors work must vary enormously as also the extent to which they want to assume all possible clinical responsibility for their patients. In the past they have been dependent on the use of hospital outpatient departments and/or the special departments to which they have had access, open or otherwise. In the early days of the Health Service there may have arisen a greater trend to refer patients to outpatient departments but there is no doubt that, given the facilities, general practitioners are ready and willing to assume increased responsibility and to practise the varying skills for which they have been trained.

Where a family doctor can undertake the care of a patient, and the organization of any investigations that are required, throughout a particular medical incident, there is no doubt that he will get greater satisfaction from his work and also his status and stature in the eyes of his patient will be enhanced. The patient, too, will benefit by the more personal relationship and the fact that he will not have to tell his troubles and their history to stranger.

In the health centres to be provided und Section 21 of the Act it was intended that the should be provided on a scale of one to approx mately 15,000 of the population and were to contain suites for both general practitioners and dentists. They would also include local healt authority clinics of various types and ancillar medico-social workers, on the principle that the preventive and curative aspect of medicine should be integrated and kept together. Owing to varying factors and difficulties the implementation of these plans was slow and there was an agreed postow ponement of the scheme, with the idea that secones thoughts might be advisable, particularly in the planning of the centres and the facilities to be provided in them. Since that time a certain numeo ber have been established, some in old buildings adapted for the purposes, and others in relation to the needs of new towns. They vary very considert ably in size and few of them provide diagnostio facilities.

In the development of general practition services it is incontrovertible that one of the mos important requirements of a family physician is access to diagnostic facilities; when this is cogne bined with the ability to carry out special investigations himself and minor operative procedureso can be assumed that he is equipped to carry ou general practice under the best possible condition and to carry out the skills required of him.

All these amenities are provided at the South $\stackrel{\mathbb{Q}}{\mathcal{O}}$ East London General Practitioner Centre, and $\overrightarrow{\vec{Q}}$ when space allows, it may be possible to in corporate in the Centre more of the preventive an social aspects of medical care than exist at the moment. Its great asset is that doctors do not carry out their practices in it, they are in no way in: competition one with another, but all are given the opportunity to practise better medicine. Healtio centres cannot be regarded as an economig proposition, but the cost of establishing centres such as this must be less than that of the healtr centres conceived in the Act, and may be of hel in the development of the Hospital Plan presented. to Parliament by the Minister of Health in January 1962, by taking some of the outpatienit load off the district hospital, a load which cannow be anything but very much heavier than existeg before, if there is to be closure of so many hospitals and concentration of the work at a comparativel small number.

The proof of one year's work has shown whato can be achieved in a diagnostic centre of this kin $\Phi$ and the interest in their work that exists amongs general practitioners when given the opportunity 
One cannot over-emphasize the value of a good common room in the development of such a unit as a local medical centre.

As the South-East London Centre exists it can provide the blue-print for an economic unit in populous areas where there are a large number of practising doctors, but in the building of new hospitals and the development of existing ones as district hospitals in other areas and smaller towns, the essentials of the Centre could well be incorporated to meet the expressed needs of the local general practitioners.

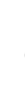

